\title{
Fan motives for interacting on social media - the example of the International Table Tennis Federation and Facebook
}

\author{
Mathias Schubert ${ }^{1, *}$ \& Jannis Seyffert ${ }^{1}$ \\ 1 Institute of Sport Science, Department of Sport Economics, Sport Sociology and Sport History, Johannes Gutenberg-University Mainz, Germany \\ * Corresponding author: Institute of Sport Science, Department of Sport Economics, Sport Sociology and Sport History, Johannes Gutenberg- \\ University Mainz, Johann-Joachim-Becher-Weg 31, 55099 Mainz, Germany, Tel: +49 61313923510 , \\ Email: schubert.m@uni-mainz.de
}

\section{ORIGINAL ARTICLE}

\section{Article History:}

Submitted $10^{\text {th }}$ July 2017

Accepted $7^{\text {th }}$ September 2017

Published $2^{\text {nd }}$ November 2017

Handling Editor:

Otmar Weiß,

University of Vienna, Austria

Editor-in-Chief:

Martin Kopp

University of Innsbruck, Austria

\section{Reviewers:}

Reviewer 1:Torsten Wojciechowski, University of Applied Sciences

Kufstein, Austria

Reviewer 2: Elsa Kristiansen, University College of Southeast Norway

\begin{abstract}
Social media has become an important tool for sport organisations to interact with fans. In particular for sports that have smaller marketing budgets and that do not receive mainstream media coverage on a daily basis, social media platforms provide unique communication and marketing opportunities to overcome such challenges. This study investigates the motives of fans to communicate on the Facebook page of the International Table Tennis Federation (ITTF). It is the first study that focuses on the use of social media in the context of an international sport federation. Knowledge about the gratifications sought by fans while interacting on social media is important for organisations to develop more customised online content, as this may help to reach further goals such as maintaining public interest, reinforcing brand awareness or developing closer relationships with stakeholders. By identifying eight categories in our data that help understand the motives for interacting on Facebook, we extend the academic understanding of sport fans' motives in the context of social media. Among the most frequent fans' motives were the desire to demonstrate expertise and express emotional attachment as well as to seek and provide information. Based on our findings, we derive implications that can be relevant for managers of (niche) sport organisations with limited financial and personal resources. The first and most straightforward recommendation is to appeal to fans' motives when interacting on social media. Making sport fans feel that their voices are heard is also crucial for increasing engagement and trust as well as strengthening relationships.
\end{abstract}

Keywords:

Communication - relationship marketing - fan engagement - gratifications - co-creation

Citation:

Schubert, M. \& Seyffert, J. (2017). Fan motives for interacting on social media - the example of the International Table Tennis Federation and Facebook. Current Issues in Sport Science, 2:004. doi: 10.15203/CISS_2017.004

\section{Introduction}

From 2000 to 2016, the number of internet users has increased from 0.4 bn to 3.1 bn (Statista, 2016a). Social media usage in particular has become an extremely popular activity and social networks like Facebook with around 1.71 bn monthly active users (Statista, 2016b) provide an attractive platform for social engagement and exchange. Along with the rapid rise of social media, tools and strategies of organisations for communicating with customers have changed significantly (Mangold \& Faulds, 2009): Companies focus on social media to influence their customers and these, in turn, make use of it to communicate with each other at whatever time, place and rate suits them best (Stavros, Meng, Westberg, \& Farrelly, 2014). That way, social media can be a reciprocal communication tool and especially feasible to engage fans, which is why also sport organisations have noticed the benefits of platforms such as Facebook, Twitter or Instagram and try to incorporate them into their overall mar- 
keting, communication, and brand management strategies. An investigation of social media use of the Association of Summer Olympic International Federations (ASOIF) revealed that all 28 members have platforms or use Facebook, Twitter and Youtube. Many sport organisations seek to develop relationships with current and potential consumers through social media by creating brand communities that customers can identify with (Vries, Gensler \& Leeflang, 2012). Through the development of both innovative and interactive experiences, they aim to develop a high level of commitment and engagement of followers (Belot, Winand, \& Kolyperas, 2016). Commitment and engagement of fans, in turn, is highly useful considering that the environment of sport organisations is extremely competitive (Hopkins, 2013; Meng, Stavros, \& Westberg, 2015; Stavros et al., 2014). As social media is increasingly becoming a platform for sport fans to interact and engage with their favourite sport brands (Thompson, Martin, Gee, \& Eagleman, 2014), sport organisations need to engage with these fans in order to retain and enhance fan bases (Pegoraro, 2010). Sport organisations that fail to meet these challenges face the risk of losing their fans and the opportunities of social media (Thompson et al., 2014).

Eagleman (2013) explains that especially for niche sports, social media offer a unique marketing and communications method to overcome challenges such as low marketing budgets. Miloch \& Lambrecht (2006) understand niche sports as sports that do not appeal to a mass audience. Greenhalgh, Simmons, Hambrick \& Greenwell $(2011,42)$ add that "niche sport properties do not have the luxury of daily news coverage in the local and national newspaper sports sections". These challenges also hold true for table tennis and the sport's highest governing body worldwide, the International Table Tennis Federation (ITTF): Despite having a long tradition in many countries worldwide and a large number of players on a global level, table tennis is still considered a niche sport (cf. Greenhalgh et al., 2011) in many parts of the world and does not receive large mainstream media coverage on a daily basis, with the exception of some Asian countries such as China or Japan. This combined with low marketing budgets as compared to major sports like football or basketball, the full utilisation of traditional marketing outlets like television or radio commercial is very difficult to achieve for the ITTF. Therefore, the federation must seek alternative methods from mainstream media and traditional marketing. In this sense, social media appears as a low-cost solution to get into touch with fans and consumers. All these features make the ITTF a paradigmatic example for niche sports, providing an interesting case to study.

In order to improve marketing communication online as well as to develop closer relationships with fans it is crucial to identify the motives of and gratifications sought by sport consumers for using social media (Filo \& Funk, 2005). A better understanding of fans' communication motives enable organisations such as the ITTF to create more customized online content, what may eventually also help to reinforce brand awareness, reach more fans and stakeholders, and maintain public interest (Eagleman, Pedersen, \& Wharton, 2009; Eagleman, 2013). Based on these ideas, the aim of this study is to explore the motives of fans to communicate on ITTF's Facebook page. This information is not only important for the ITTF, but also in a broader context. By extending the academic understanding of sport fans' motives in the context of social media, our study may also be relevant for managers of other (niche) sport organisations that face similar challenges due to limited financial and personal resources.

\section{Literature Review}

\section{Social media as a communication and marketing tool}

The (continuous) rise of active online communities is mainly caused by the increasing accessibility of social media due to portable and wireless mobile devices such as smartphones and tablets (Hennig-Thurau et al., 2010). Today, users have the possibility to create content, listen to other users, participate in discussions, and share interests or experiences. In this way, they can be consumers, producers and distributors of information at the same time (Abeza, O'Reilly, \& Reid, 2013). Due to this technologically advanced business environment, traditional marketing practices are facing both new opportunities and challenges (Hennig-Thurau et al., 2010). The use of social media may have a positive impact on enhanced knowledge of customers, advanced customer-organisation interaction, effective customer engagement, and efficient use of resources in terms of time and money; negative consequences of social media on the other hand may include a lack of control over messages posted on social media, concerns over the credibility and reliability of information or difficulties in identifying "true" online customers (Abeza et al., 2013).

In recent years, social media has been identified as an important relationship marketing tool that enables meaningful relationships through communication and interaction (Williams \& Chinn, 2010). As the overall goal of relationship marketing is to retain customers through long-term mutual satisfaction, organisations need to implement effective communication platforms (Abeza et al., 2013). From this perspective, social media is an ideal tool for a continuing dialogue and building a two-way collaborative relationship through communication and interaction between businesses and customers (Peppers \& Rogers, 2011). An effective relationship marketing may cause greater loyalty, increased customer retention, reduced marketing costs and greater profits as well as increased stability and security (Christopher, Payne, \& Ballantyne, 2002). However, Stavros, Pope, \& Winzar (2008) remark that the successful implementation of relationship marketing requires a long-term outlook and customer focus.

\section{The use of social media in sport}

Pedersen (2014) notes that there has been an enormous increase in sports' related social media journal publications. The increasing relevance of this topic is also proved by two recent 
review articles that critically assess the history and current state of social media scholarship in sport management research (Abeza, O’Reilly, Séguin, \& Nzindukiyimana, 2015; Filo, Lock \& Karg, 2015). Scholars have investigated the use of social media in the context of sport organisations (e.g. Naraine \& Parent, 2016; O'Shea \& Alonso, 2011; Wallace, Wilson, \& Miloch, 2011), sport teams (e.g. Gibbs, O'Reilly, \& Brunette 2014; Pronschinske, Groza, \& Walker 2012; Waters et al., 2011) and athletes (e.g. Hambrick et al., 2010; Kassing \& Sanderson, 2010; Pegoraro, 2010). By examining football college sport fans' engagement in sport-focused social media, Clavio \& Walsh (2014) revealed the prevalence of interactivity and information-gathering purposes as fans' motives for using social media. Gibbs et al. (2014) confirmed that updates concerning live games and newsgathering as well as interactivity were three of the four most important motives for Canadian Football League fans. Kassing \& Sanderson (2009) examined sport fans' posts on a blog that was managed by cyclist Floyd Landis. They demonstrated that fans expressed praise and congratulations and actively gave encouragement and advice to the athlete. Stavros et al. (2014) drew on the idea of value co-creation and provided multi-layered insights into fan motives for interacting on Facebook by investigating posts of National Basketball Association (NBA) teams. The relevance of value co-creation in the social media context has also been highlighted by Filo et al. (2015), who argue that to build relationships, brands need to psychologically engage consumers in the co-creation process facilitated by social media platforms.

The idea of value co-creation can be defined as "benefit realized from integration of resources through activities and interactions with collaborators in the customer's service network" (Mccoll-Kennedy, Vargo, Dagger, Sweeney, \& Kasteren, 2016, p. 370). In line with this, organisations have started to focus no longer on creating values for consumers but on creating values with consumers (Woratschek, Horbel, \& Popp, 2014). The roles of companies and consumers have dramatically changed in the value chain of the social media era and the possibilities created by social media have allowed companies to take advantages of its features in order to realise value co-creation (Wang, Li, \& Suomi, 2016). As co-creation happens exclusively on a voluntary base and requires consumers to spend time and share knowledge, organisations need to ensure that customers are motivated to engage in co-creation activities online (Constantinides et al., 2015).

Stavros et al. (2014) found four key motives of sport fans to interact on social media: passion, hope, esteem and camaraderie. Importantly, it was found that the content posted by teams had a considerable impact on the reciprocal activities of fans. However, motivational profiles of fans of different sports vary (Wann, Grieve, Zapalac, \& Pease, 2008). Also, international sport federations use social media in a different way than sport teams do, as they do not take part in sport competitions but organise them and represent the sport in general (Belot et al., 2016). Consequently, the findings of Stavros et al. (2014) regarding fan motives to communicate on Facebook are not automatical- ly applicable to fans of international sport federations such as the ITTF. To date, there is no study available that has examined what kind of motives lead sport fans to interact on social media pages of international (niche) sport federations.

\section{The International Table Tennis Federation}

Table tennis is regarded as the fastest setback game in the world and counts more than 164 million active players and about 250 million amateur players worldwide. The ITTF is the international governing body of table tennis and includes 226 member associations - the most of any international sport federations. As such, the organisation falls within the concept of non-profit meta-organisations, as their members are not individuals but organisations themselves. The ITTF's main function is to govern and develop the sport for the benefit of table tennis players in all parts of the world. More precisely, the ITTF claims that one major goal is "to increase participation at all levels, to enhance the popularity of the sport, to develop new sources of revenue, and to manage the sport through a systematic planning process" (ITTF, 2014, p. 4). The ITTF competition calendar includes about 140 tournaments in total, with almost half of them being sanctioned and authorised by the organisation itself. The organisation has its headquarters in Singapore and lists 25 employees as professional staff in 2016, with 23 of them working full-time.

The ITTF is active on the most popular platforms, such as Facebook, Twitter, Youtube, Instagram, Flickr and Youkuas and has about 1.5 million fans across all social media platforms. The organisation's "goal is to provide table tennis fans the most engaging, interesting and up to date social media content on all available platforms" (Pound, 2017). Given that the ITTF has about ten times more followers on Facebook than on Twitter (336.616 vs. 29.174), the former was chosen as research subject in this study. The importance of social media for the ITTF is constantly growing. According to the ITTF, the organisation uses Facebook intensively in the context of events, which are considered a tool to promote the sport in general (Pound, 2017). At smaller tournaments (e.g. World Tour, World Cup), usually one employee is responsible for the social media activities, while during bigger events such as the World Championships or the Olympic Games, usually three employees are working on social media platforms about three hours a day (Pound, 2017). In the context of the Olympic Games, the ITTF is subject to the IOC's media constraints on audios and videos of the events, competitions or any other activities that occur at Olympic venues. Thus, the ITTF can only share pictures, videos and audios from outside the Olympic venues on Facebook.

In order to ensure a minimum control over the content posted, the ITTF's Facebook proxies only allow fans to reply on posts initiated by the ITTF itself. Furthermore, due to personnel and financial constraints, interaction between the ITTF and the fans is limited (Pound, 2017). Furthermore, the organisation lacks resources to comprehensively examine comments as well as 
Facebook analytics and it is thus acknowledged that the opportunities of Facebook are not exploited to its full extent (Pound, 2017). Given these constraints, there is a need to develop innovative as well as interactive experiences, in order to affect the level of commitment and engagement of followers.

\section{Methods}

Pedersen (2013) and Filo et al. (2015) highlight the need in scholarship to focus on the strategic use of social media by sport organisations. In line with this call, our study adopts a multiple methods approach: the qualitative content analysis of the ITTF Facebook page was guided and supported by frequent electronic interaction with the ITTF at critical stages throughout the research process. Furthermore, two semi-structured expert interviews with representatives from the ITTF were conducted.

\section{Content Analysis of the ITTF Facebook page}

The comments on ITTF's Facebook page were collected for the period of July 29 to August 232016 - that is, one week before, during, and after the table tennis competitions at the Olympic Games in Rio de Janeiro. This period was chosen as it was considered a time with a high degree of social interaction on the Facebook page. Data collection was assisted by using Facepager 3.6, a software that allows to automatically gather public data available on Facebook or Twitter (Ludwig-MaximiliansUniversität, 2016). In total, 10.601 Facebook comments were posted during the stated time.

The different steps of text analysis draw from qualitative content analysis, which is, perhaps, one of the most common methods of data analysis used in qualitative empirical research. The approach was considered useful in this context as it enables researchers in an unobtrusive, covert and cost effective way to provide rich insights into consumers' interaction online (Kozinets, 2002; Langer \& Beckman, 2005). In particular, we adopted the procedure as outlined by Mayring (2000). Mayring (2000, para. 5) defines this method "as an approach of empirical, methodological controlled analysis of texts within their context of communication, following content analytical rules and step by step models". Given the paucity of similar research on sport fans' motives for the use of an international federation's social media pages, categories were built through an inductive coding procedure. Our analytical focus, however, was influenced by the findings of related research. By developing categories out of the material, the aim was to reduce the material on another level of abstraction while keeping the main content. It is important to note that this is a strict rule-governed procedure, in the sense that the same procedure is applied to the whole material. Due to research economic reasons as well as language barriers, only comments in English and German were analysed. 3,375 comments were excluded as they were either written in languages other than English or German or ambiguous (e.g. a comment merely consisting of "..."). In total, 6,915 comments by sport fans as well as 291 posts and 20 comments of the ITTF entered the coding process.

In line with Mayring (2000), the coding unit was defined as clear semantic elements in comments created by fans. Thus, a comment consisted of one semantic element (one motive) or several semantic elements (several motives). Defining the coding unit helped to break down the data into parts and to develop categories for motives (Mayring, 2000). A category was formed once a coding unit fitted the selection criterion. The next time an appropriate coding unit appeared, the unit was either assigned to previous categories or a new category was created (Mayring, 2014). In a few case, multiple assignment of units to categories was conducted. While re-reading the comments several times, a better understanding of the data could be gained (Hsieh \& Shannon, 2005). After working through 70\% of the data material, no more new categories could be detected. In line with Mayring's (2014) recommendations, a revision of the whole category system was subsequently conducted. All comments were then worked through once again. Finally, we pooled subcategories into a smaller number of main categories in order to get a clear picture of sport fans' motives.

By reviewing the texts multiple times and piece by piece, the lead author was able to better absorb and become more familiar with the data (cf. Guest, MacQueen, \& Namey, 2012). Intersubjective verifiability (intra-coder reliability) was ensured through regular consultations with the research team, in which specific sections of the data and how they relate to categories were discussed. The aim of the analysis team was to reach agreement on the interpretation of data extracts through constant revisions of category definitions and the coding system.

\section{Expert interviews with ITTF representatives}

Experts have a privileged access to information and have a high level of aggregated and specific knowledge, which is difficult to access otherwise. A face-to-face interview with the federation's president Thomas Weikert took place on January 4th 2017 in his office in Germany. As marketing and media manager Matt Pound is based at the ITTF headquarter in Singapore, a Skype interview was conducted on January 5th 2017. Both interviews were recorded. The analysis of each expert interview was conducted according to Meuser \& Nagel's (1991) six steps evaluation procedure. First, the interviews were transcribed. Second, they were chronologically paraphrased, which helped to identify central topics and to reduce the material. Third, the paraphrased material was sorted by adding headlines. Paraphrases, which did not refer to the research question in a broader sense were excluded. If the same interview is conducted with different persons, the fourth step would usually involve merging the paraphrased material of all interviews that were held. As in this study only two different interviews were conducted, this step did not need to be performed. The fifth step includes the building of a category scheme. This step was also not carried out, as the aim of the expert interviews was not to develop a new framework, but to clarify questions and to get insights into 
ITTF's social media appearance. Finally, all headlines and their corresponding text passages were interpreted. In the following section, the results of both expert interviews are inserted where appropriate.

By combining two methods within our study, our approach helped to reduce the likelihood of misinterpretation with the target and to clarify meaning of our observations and interpretations (Edwards \& Skinner, 2009). It allowed us to get a more holistic understanding of the use of social media in our context.

\section{Results}

ITTF posts

During the time of interest, the ITTF created 291 posts in total with an average of 12 posts per day. Information about upcoming matches, live scores as well as final results of matches and background information about players and teams were posted. The vast majority of posts was underlined by pictures (203), followed by videos (45) and links (43). Most pictures showed players participating in the Olympic Games. Given that the ITTF was not allowed to post videos from inside the venues, videos mainly represented unique shots or rallies of participating players from matches that had taken place before the Olympic Games. The ITTF did not only provide information, but also tried to encourage their sport fans to get engaged. $24 \%$ of the posts contained fan-directed questions, mostly asking for predictions and opinions (e.g. "Who will be the \#Rio2016 Olympic Table Tennis Champions?"). Also other forms of call-to-actions (e.g. "Feedback is welcome") could be observed. Research has shown that the type of content posted by the organisation influences both the number of comments as well as the (diverse) cognitive, affective, and behavioural outcomes of consumers' comments (van Noort, Voorveld \& van Reijmersdal, 2012). Such reciprocal effects could also be found in our study: in contrast to merely presenting information, ITTF's posts at the Olympic Games mainly carried an emotional style of writing, what acted as a catalyst for interactivity. However, ITTF's participation in discussions was an exception (20) and mainly of a neutral, informative nature. These findings confirm the ITTF's policy that it does not want to get involved in typical sport fans' chats about table tennis and merely writes comments when a question directly addresses the organisation or people are asking for advice (Pound, 2017).

\section{Fan motives}

6.915 comments were created by 3.409 sport fans - which sums up to 277 posts per day. $82 \%$ of sport fans created up to three comments during the Olympic Games. $2 \%$ of sport fans were identified as very active users who wrote more than ten comments during the three and a half weeks. One sport fan even wrote 57 comments in total. These numbers outline that the vast majority did not write on a daily basis on the ITTF Facebook page.

The data in this study indicate eight categories that emanate from the comments of individuals on the ITTF Facebook page, which help understand the motives for interacting on social media: expertise, passion, support, help, quiz participation, esteem, camaraderie and criticism. Figure 1 shows these categories (i.e. motives) and sub-categories as well as their quantities.

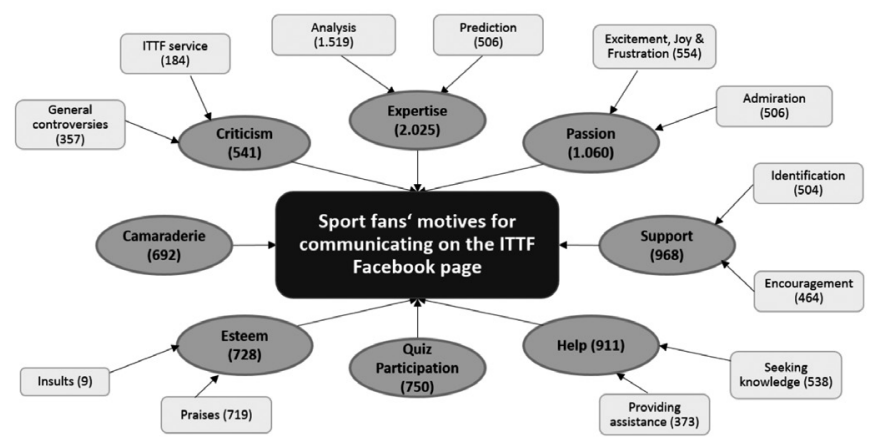

Figure 1: Sport fans' motives for communicating on ITTF's Facebook page

Some of the motives (passion, esteem, camaraderie) have been broadly identified in previous research (Stavros et al., 2014) on social media, yet in other contexts and with a distinct understanding and interpretation. Each motive will be explained in the following. The categories, and sub-categories as well as their definitions and illustrative examples are presented in Table 1.

Expertise. The data revealed that in most of the comments (2.025) fans expressed their expertise and had the desire to share knowledge. This category mainly contains analyses (1.519) of past and predictions (506) of upcoming matches. These findings emphasize the importance of giving sport fans the opportunity to exchange and discuss thoughts, opinions and facts on social media. Interactions here were characterised by intensive discussions in which different opinions of fans were often followed by a variety of other comments. As Raban \& Rafaeli (2007) mentioned, sharing knowledge can serve to enhance one's self-image, especially if respect from others can be gained. Thus, the increase of self-esteem after receiving positive feedback for sharing knowledge can be considered as one of the major factors for sharing knowledge (Chan, Bhandar, Oh, \& Hock-Chuan, 2004). In fact, approvals as well as rejections could be observed and characterised follow-up expressions by fans. Most of the comments in this category were longer, emotionless statements.

Sport fans had the desire to actively deal with matches even before they had started. Predictions and reasons were explained why a specific player or team would win or lose. If so, these comments were often answered by other sport fans articulating their point of view. Especially during the matches, fans were discussing players' skills, superior game systems, critical referee decisions as well as player and team tactics. Inter- 
acting on social media platforms while watching a sport event ("second screening") is a widespread phenomenon and increases the engagement of sport fans (Giglietto \& Selva, 2014; Tang \& Cooper, 2011).

Passion: This category (1.060) contained comments reflecting excitement, joy \& frustration (554) as well as admiration (506) for players or teams. Previous research has shown that individuals seek sport event experiences due to opportunities for mental action and excitement (Funk, Filo, Beaton, \& Pritchard, 2009). Hwang \& Lim (2015) pointed out that excitement motives are most important for sport television viewing. Based on our data it became obvious that many fans had the desire to demonstrate fascination on Facebook. Especially during the matches, fans wrote comments representing their emotional attachment to the matches. After matches, sport fans felt the desire to express their state of mood. Prior research found that losses and wins can have a strong effect on the mood states of fans; after negative outcomes of their favourite players or teams, sport fans need to get along with immediate negative feelings (Wann, Friedman, McHale, \& Jaffe, 2003). Therefore, comments reflecting fans' sadness, anger, and disappointment can be seen as coping mechanisms that are used to handle negative emotions. These coping strategies are more likely to be used by highly involved fans, as they are more emotionally attached and thus benefit more from these mechanisms (Wann, Grieve, Zapalac, Visek, Partridge, \& Lanter, 2011). Similarly, demonstrating joy may reinforce this state of mood (Watkins, 2004). Many statements in this category were very emotional, such as demonstrating adoration for individual players. Interestingly, the majority of comments was characterised by almost no followup interactions.

Support: This category (968) is also characterised by highly emotional comments containing identification (504) with certain players or teams as well as encouragement (464) for them. All comments contained explicit and implicit statements that had supportive effects on players and teams, demonstrating the intense attachment of fans. The emotional way of support emphasises the importance of giving sport fans the opportunity to express identification and encouragement not only in the venue, but also in other contexts like social media (Stavros et al., 2014). This appears even more important when taking into account that most sport fans cannot actively participate in the venue as they live all over the world. Many times comments reflected the desire to encourage specific players or teams in a direct way. Players were often called by their first name which created the impression of closeness. Writing player-directed comments of an intimate nature is a well investigated phenomenon and emphasizes the desire for a close bond with players (Chia \& Poo, 2009). Fans sought to demonstrate their identification (i.e. level of psychological attachment, Kim \& Kim, 2009) with their favourite players or teams. Some fans added weight to their statements by using capital letters and exclamation marks. Hope was a recurring theme within this category. Snyder (2000) stated that hope can vary significantly depending on how much meaning fans ascribe to players and their wins.
Our data revealed that the majority of such comments was generated in advance of the semi-finals and finals. As players were getting closer to the medal matches, sport fans possibly felt more attached which triggered the desire for sharing their hope. Another interesting finding was that sport fans also expressed their hope for players whose chances for winning were rather low according to the world ranking.

Help: Seeking knowledge (538) and providing assistance (373) formed another category called help (911). Previous research outlined that social media is increasingly used for gathering information (Stavros et al., 2014). Especially on social media brand pages on which users with the same interests connect, chances to find users who are willing to share information are high (Bian, Liu, Agichtein, \& Zha, 2008). Thus, the ITTF Facebook page seems ideally suited for sport fans to gather information. In fact, the data in this study revealed that sport fans were not only motivated to seek information but also to provide assistance by answering questions. The page was considered an appropriate and trusted source. Comments reflected the desire to learn more about players' backgrounds as well as their playing equipment. In many comments, live stream links as well as result updates and player information were shared. In some cases, instructions for broadcasting and help via private message were even offered without prior requests. Sport fans might have answered questions in order to boost their self-esteem (Ardichvili, Page, \&Wentling, 2003). Furthermore, aspects of group belongingness and sociability as well as altruistic motives might have been the reason for doing so (Cheung \& Lee, 2012).

Quiz Participation: This category (750) reflects the motive of taking part in different kind of quizzes. Quizzes are a typical feature on brand fan pages on Facebook (Vries et al., 2012) and also the ITTF organised several quizzes on its page, such as guessing games in which fans were supposed to guess which player had signed and painted a ball. By giving the correct answer via comments, fans had the chance to win this ball. Similar to previous categories, sport fans that commented on these quizzes also had the chance to express their knowledge by mentioning the correct answer. Typically, comments in this category were short and did not encourage further discussion.

Esteem: Praises (719) and insults (9) regarding players or teams formed the category esteem (728). Many of the fans posted comments in order to express congratulations after a match was finished. These comments most often directly addressed players or teams and encompassed mainly acknowledgments of their performances. Even if most of the time sport fans articulated praise after their favourite player or team had won, several times the performance of the loser was acknowledged as well. Kassing \& Barber (1997) illustrated that congratulating the opponent is considered as a part of sportsmanship. Therefore, congratulations may also be demonstrated by supporters of the loser as an action of showing respect for the opponent. The data showed that comments which contained insults of players or teams only hardly existed. This is worth mentioning as the number of aggressive, offensive and emotional comments 
Table 1: Codebook extract showing categories, definitions and illustrative examples

\begin{tabular}{|c|c|c|c|}
\hline CATEGORY & SUB-CATEGORIES & WHEN TO USE & ILLUSTRATIVE EXAMPLE \\
\hline \multirow[t]{2}{*}{ Expertise } & Analysis & $\begin{array}{l}\text { Evaluation of and facts about a player or } \\
\text { team or match }\end{array}$ & $\begin{array}{l}\text { "Yeah Right, \#TeamAustria was permitted } \\
\text { to totally bullshit in the 4th game (player } \\
\text { Stefan Fegerl ruined João Monteiro con- } \\
\text { centration by pretending that there was } \\
\text { a problem with a ball and soon after by } \\
\text { pressing the referee to take back a service } \\
\text { point from the Portuguese player that } \\
\text { would give the 9-5) and that had a major } \\
\text { influence in a tight game." }\end{array}$ \\
\hline & Prediction & $\begin{array}{l}\text { Evaluation of a player's or team's likeli- } \\
\text { hood of success }\end{array}$ & $\begin{array}{l}\text { "As far as I concern, he's not going to beat } \\
\text { Ovtcharov...because of his powerful back- } \\
\text { hand loop....even though ZJK's backhand } \\
\text { is good." }\end{array}$ \\
\hline Passion & Admiration & $\begin{array}{l}\text { Affection for a player or team and its ap- } \\
\text { pearance }\end{array}$ & "Love A Fukuhara so much" \\
\hline \multirow[t]{2}{*}{ Support } & Identification & $\begin{array}{l}\text { Perception of belonging to a player or } \\
\text { team }\end{array}$ & "Rooting for \#TeamGermany!!!" \\
\hline & Encouragement & $\begin{array}{l}\text { Act of giving a player or team support for } \\
\text { upcoming matches }\end{array}$ & "Go Vladimir Samsonov beat ZJK" \\
\hline \multirow[t]{2}{*}{ Help } & Seeking knowledge & $\begin{array}{l}\text { Posing questions about a player or team } \\
\text { or match or table tennis issues in general }\end{array}$ & "Who lost their point from Germany?" \\
\hline & Providing assistance & $\begin{array}{l}\text { Responses to questions about a player or } \\
\text { team or match or table tennis issues in } \\
\text { general }\end{array}$ & $\begin{array}{l}\text { "He's always used T05. Blade handle ap- } \\
\text { pears to be a donic. Could be anything } \\
\text { under the rubbers" }\end{array}$ \\
\hline Camaraderie & & $\begin{array}{l}\text { Interaction within the community for the } \\
\text { purpose of creating and maintaining re- } \\
\text { lationships }\end{array}$ & $\begin{array}{l}\text { "Jay Muecke when u coming back to win- } \\
\text { ter pennant? we have all missed u and } \\
\text { give u and ur shoulder best wishes." }\end{array}$ \\
\hline \multirow[t]{2}{*}{ Criticism } & General controversies & $\begin{array}{l}\text { Positive and negative comments in re- } \\
\text { sponse to current table tennis issues }\end{array}$ & $\begin{array}{l}\text { "China generally means lights out for the } \\
\text { opponent" }\end{array}$ \\
\hline & ITTF service & $\begin{array}{l}\text { Positive and negative comments in re- } \\
\text { sponse to ITTF services }\end{array}$ & $\begin{array}{l}\text { "The website looks great and I cant wait } \\
\text { for the ittf to completly change to this } \\
\text { website" }\end{array}$ \\
\hline
\end{tabular}

on social media has dramatically increased over the last years (Rost, Stahel, \& Frey, 2016).

Camaraderie: This category (692) represents general social interactions that do not primarily refer to table tennis issues, but are entered for the purpose of creating and maintaining relationships. Research has shown that main motives for the use of social media are to develop identities, to stay in contact with friends and to foster relationships (Pegoraro, 2013). The fact that sport fans visited ITTF's Facebook page clearly demon- strated the desire for a group identity by meeting like-minded people and being part of the "table tennis family". Comments in this category typically did not refer to table tennis directly but were written with the purpose of addressing specific users. Fans sought to integrate their own practical table tennis experiences into their statements. Also comments reflecting the desire of self-disclosure (e.g. "I lost 10 Euros" or "I missed my flight LoL") could be observed. Messages about the self that sport fans communicate to peers were found to be an impor- 
tant communication behaviour on Facebook (Ledbetter, Mazer, DeGroot, Meyer, Yuping, \& Swafford, 2011).

Criticism: General controversies (357) and critical comments concerning ITTF services (184) formed the last category called criticism (541). Sport fans' motives in this category were found to be similar to the motives for expressing expertise. Similar to sharing knowledge, expressing criticism can increase fans' selfesteem by obtaining approval from others (Raban \& Rafaeli, 2007). In contrast to the category expertise, comments in this category also included the desire for improvement in the future. Broadcasting problems during the Olympic Games were discussed in particular, as many of the sport fans were disappointed about the table tennis coverage in television and online. The ITTF commented on this problem by explaining that the Games were owned by the IOC, which is why access to live streams could not be offered. Some comments emphasized fans' disappointment in the ITTF for not buying the media rights for the Olympic Games. The large number of comments that included criticism against broadcasting issues highlighted fans' desire to watch table tennis matches online. Another critical issue discussed by sport fans was the Chinese domination of table tennis. As China has won 28 of the 32 Olympic gold medals since table tennis was introduced to the Games, it was hardly surprising that many fans wrote comments in which they expressed their boredom due to the predictability of results. In addition, the naturalisation of Chinese players was controversially discussed.

\section{Discussion and managerial implications}

This is the first study to date that has examined the motives of sport fans for interacting on a social media forum of an international (niche) sport federation. Our results are relevant in several areas on a global scale for both academia and practice. By confirming motives identified in previous studies as well as detecting novel motives for being active on a sport organisation's Facebook page, we extend the academic understanding of sport fans' motives in the context of social media. Our findings can thus be used by scholars to provide guidance and investigate social media usage by other organisations.

Based on our findings, we derived practical implications to the ITTF that can also be relevant for managers of other (niche) sport organisations that face similar challenges due to limited financial and personal resources. The first and most straightforward recommendation is to appeal to fans' motives when interacting on social media. Our data indicates that demonstrating expertise was by far the most important gratification sought. Sport managers can capitalise on that by demanding "expert" knowledge from fans when it comes to match analyses and predictions. This motive could also be addressed by making use of the various quiz options Facebook offers. Due to the algorithm of Facebook, the higher the amount of comments, the longer it will stay on people's timeline and thus the higher the visibility and reach. Therefore, open questions may help to engender meaningful follow-up conversations among users. Previous research has highlighted the importance of "micro-dialogues" between the organisation and highly engaged audiences (Eagleman, 2013). Also Stavros et al. (2014) note that fans seeking to share their knowledge are more likely to be expecting a response from the organisation. Therefore, making sport fans feel that their voices are heard is crucial for increasing engagement and trust as well as strengthening relationships. The ITTF currently lacks resources for systematic interaction with its fans and it is also acknowledged that the opportunities of Facebook are not exploited to its full extent (Pound, 2017). Given the increasing importance of social media for marketing purposes, the organisation is planning to recruit new staff in this field (Weikert, 2017). In line with the idea of co-creation, another low-cost strategy could be to identify highly active and engaged fans and assign them "official" moderator duties on a freelance basis. Carefully selected fans could, for example, act as discussion leaders or "watch-dogs" and assist the ITTF while satisfying their own motives at the same time. This may eventually enhance the development of trust and strengthen the relationship to fans (Eagleman, 2013).

Based on our data, fans seek to express their passion, admiration and support for players or teams. This motive could be addressed by increasingly promoting star players and by providing fans the opportunity to interact with them. A best practice example was provided by the 2016 NBA All-Star Weekend, where Facebook's "live" function was used for 60-second live interviews between star players and fans (Facebook, 2017). Activities like this give fans the possibility to gratify their motives in a new and more authentic way, since they would be able to communicate with their favourite players directly.

Eagleman (2013) has found that many national governing bodies of sport simply use social media as a communication tool and miss out on a valuable opportunity to capitalise on its marketing capabilities. This seems careless, as sport consumers who visit an organisation's website more frequently indicated a greater likelihood to purchase from sponsors (Eagleman \& Krohn, 2012). As of 2017, the ITTF has ended its partnership with a marketing agency and now holds all commercial rights itself. Recent initiatives indicate that the attractiveness of potential sponsorships has increased (Weikert, 2017). Social media can provide an effective and efficient tool in this regard, for example by promoting or activating sponsorships.

\section{Limitations and future research}

The findings of this study can help the ITTF as well as other international (niche) sport federations to better capitalise on the communication and marketing capabilities of social media. However, our study is also characterised by a few (de-)limitations that should be addressed. First, we only analysed comments on the ITTF Facebook page that were either in English and German language and thus missed out all other posts. Fur- 
thermore, as Facebook is blocked in China, the largest fan base and probably most important market for the ITTF has not been considered in our study. Future research should therefore also try to investigate motives on the ITTF's presence on Chinese social media such as Sina Weibo. Second, the period of investigation was during the 2016 Olympic Games, where the ITTF was not allowed to share any content from inside the venues. Thus, another research opportunity is to investigate the gratifications sought by fans in settings where live coverage of the organisation is possible (such as World Championships or World Cups).

\section{Funding}

The authors have no funding or support to report.

\section{Competing Interests}

The authors have declared that no competing interests exist.

\section{Data Availability Statement}

All relevant data are within the paper.

\section{References}

Abeza, G., O'Reilly, N., \& Reid, I. (2013). Relationship marketing and social media in sport. International Journal of Sport Communication, 6(2), 120-142. doi: 10.1123/ijsc.6.2.120

Abeza, G., O'Reilly, N., Séguin, B. \& Nzindukiyimana, O. (2015). Social media scholarship in sport management research: $A$ critical review. Journal of Sport Management, 29(6), 601-618. doi: 10.1123/JSM.2014-0296

Ardichvili, A., Page, V., \&Wentling, T. (2003). Motivation and barriers of participation in virtual knowledge-sharing communities of practice. Journal of Knowledge Management, 7(1), 64-77. doi: 10.1108/13673270310463626

Belot, M., Winand, M., \& Kolyperas, D. (2016). How do International Sport Federations communicate through social media: A content analysis of FIFA's Twitter communication. Faculty of Health Sciences and Sport Conference Papers and Proceedings. Retrieved from http://hdl.handle. net/1893/24321

Bian, J., Liu, Y., Agichtein, E., \& Zha, H. (2008). Finding the right facts in the crowd: factoid question answering over social media. Proceedings of the 17th International Conference on World Wide Web, 467-476.

Constantinides, E., Brünink, L. A., \& Romero, C. L. (2015). Customer motives and benefits for participating in online co-creation activities. International Journal of Internet Marketing and Advertising, 9(1), 21. http://doi.org/10.1504/ IJIMA.2015.068346
Chan, C. M. L., Bhandar, M., Oh, L.-B., \& Hock-Chuan, C. (2004). Recognition and participation in a virtual community. Proceedings of the 37th Annual Hawaii International Conference on System Sciences, 1-10. doi: 10.1109/HICSS.2004.1265460

Cheung, C. M. K., \& Lee, M. K. O. (2012). What drives consumers to spread electronic word of mouth in online consumeropinion platforms. Decision Support Systems, 53(1), 218225. doi: 10.1016/j.dss.2012.01.015

Chia, S. C., \& Poo, Y. L. (2009). Media, celebrities, and fans: an examination of adolescents' media usage and involvement with entertainment celebrities. Journalism and Mass Communication Quarterly, 86(1), 23-44. doi: 10.1177/ 107769900908600103

Christopher, M., Payne, A., \& Ballantyne, D. (2002). Relationship marketing: Creating stakeholder value. Oxford, UK: Butterworth-Heinemann.

Clavio, G., \& Walsh, P. (2014). Dimensions of social media utilization among college sport fans. Communication and Sport, 2(3), 261-281. doi: 10.1177/2167479513480355

Eagleman, A. N. (2013). Acceptance, motivations, and usage of social media as a marketing communications tool amongst employees of sport national governing bodies. Sport Management Review, 16(4), 488-497. doi: 10.1016/j. smr.2013.03.004

Eagleman, A. N., Pedersen, P. M., \& Wharton, B. (2009). Coverage by gender in ESPN. The Magazine: An examination of articles and photographs. International Journal of Sport Management, 10(2), 226-242.

Eagleman, A. N., \& Krohn, B. D. (2012). The impact of road race series participants' internet usage on sponsorship recognition and purchase intentions. Sport Marketing Quarterly, 21(4), 210-220.

Edwards, A. \& Skinner, J. (2009). Qualitative Research in Sport Management. Oxford: Elsevier.

Facebook. (2017). NBA Goes Global with Facebook Live During All-Star Break. Retrieved from https://media. fb.com/2016/02/15/nba-facebook-live-all-star-break/

Filo, K., \& Funk, D. C. (2005). Congruence between attractive product features and virtual content delivery for internet marketing communication. Sport Marketing Quarterly, 14, 112-122.

Filo, K., Lock, D., \& Karg, A. (2015). Sport and social media research: A review. Sport Management Review, 18(2), 166-181. doi: 10.1016/j.smr.2014.11.001

Funk, D. C., Filo, K., Beaton, A. A., \& Pritchard, M. (2009). Measuring the motives of sport event attendance : bridging the academic-practitioner divide to understanding behavior. Sport Marketing Quarterly, 18(3), 126-138.

Gibbs, C., O'Reilly, N., \& Brunette, M. (2014). Professional team sport and twitter: gratifications sought and obtained by followers. International Journal of Sport Communication, 7(2), 188-213. doi: 10.1123/IJSC.2014-0005

Giglietto, F., \& Selva, D. (2014). Second screen and participation: a content analysis on a full season dataset of tweets. Journal of Communication, 64(2), 260-277. doi: 10.1111/jcom.12085 
Greenhalgh, G.P., Simmons, J.M., Hambrick, M.E., \& Greenwell, T.C. (2011). Spectator support: Examining the attributes that differentiate niche from mainstream sport. Sport Marketing Quarterly, 20, 41-52.

Guest, G., MacQueen, K. M. \& Namey, E. E. (2012). Applied thematic analysis. Los Angeles: SAGE.

Hambrick, M. E., Simmons, J. M., Greenhalgh, G. P., \& Greenwell, T. C. (2010). Understanding Professional Athletes' Use of Twitter: A Content Analysis of Athlete Tweets. International Journal of Sport Communication, 3(4), 454-471. http://doi. org/10.1123/ijsc.3.4.454

Hennig-Thurau, T., Malthouse, E. C., Friege, C., Gensler, S., Lobschat, L., Rangaswamy, A., \& Skiera, B. (2010). The impact of new media on customer relationships. Journal of Service Research, 13(3), 311-330. doi: 10.1177/1094670510375460

Hopkins, J. L. (2013). Engaging australian rules football fans with social media: A case study. Journal of Sport Management and Marketing, 13(1-2), 104-121. doi: 10.1504/ IJSMM.2013.055197

Hsieh, H.-F., \& Shannon, S. E. (2005). Three Approaches to Qualitative Content Analysis. Qualitative Health Research, 15(9), 1277-1288. doi.org/10.1177/1049732305276687

Hwang, Y., \& Lim, J. S. (2015). The impact of engagement motives for social TV on social presence and sports channel commitment. Telematics and Informatics, 32(4), 755-765. doi: $10.1016 /$ j.tele.2015.03.006

ITTF. (2014). International Table Tennis Federation Annual General Meeting and Board of Directors' Meeting.

Kassing, J. W., \& Barber, A. M. (1997). "Being a good sport": an investigation of sportsmanship messages provided by youth soccer parents, officials, and coaches. Human Communication, 10(1), 61-68.

Kassing, J. W., \& Sanderson, J. (2010). Fan-athlete interaction and twitter tweeting through the giro: A case study. International Journal of Sport Communication, 3(1), 113-128. doi: 10.1123/ijsc.3.1.113

Kim, Y., \& Kim, S. (2009). The relationships between team attributes, team identification and sponsor image. International Journal of Sports Marketing and Sponsorship, 10(3), 18-32. doi: 10.1108/IJSMS-10-03-2009- B004

Kozinets, R. V. (2002). The field behind the screen: using netnography for marketing research in online communities. Journal of Marketing Research, 39(1), 61-72. doi:10.1509/ jmkr.39.1.61.18935

Langer, R., \& Beckman, S. C. (2005). Sensitive research topics: netnography revisited. Qualitative Market Research: An International Journal, 8(2), 189-203. doi: 10.1108/ 13522750510592454

Ledbetter, A. M., Mazer, J. P., DeGroot, J. M., Meyer, K. R., Yuping M., \& Swafford, B. (2011). Attitudes toward online social connection and self- disclosure as predictors of Facebook communication and relational closeness. Communication Research, 38(1), 27-53. doi: 10.1177/0093650210365537

Ludwig-Maximilians-Universität. (2016). Software - Empirische Kommunikationswissenschaft - LMU München. Retrieved from http://www.ls1.ifkw.uni-muenchen.de/personen/wiss _ma/keyling_till/software.html

Mangold, W. G., \& Faulds, D. J. (2009). Social media: The new hybrid element of the promotion mix. Business Horizons, 52(4), 357-365. doi:10.1016/j.bushor.2009.03.002

Mayring, P. (2000). Qualitative Content Analysis. Qualitative Social Research, 1(20).

Mayring, P. (2014). Qualitative Content Analysis: theoretical foundation, basic procedures and software solution. Klagenfurt. Retrieved from http://nbn-resolving.de/ urn:nbn:de:0168-ssoar-395173

Mccoll-Kennedy, J. R., Vargo, S. L., Dagger, T. S., Sweeney, J. C., \& Kasteren, Y. Van. (2016). Health Care Customer Value Cocreation Practice Styles. Journal of Service Research, 15(3), 370-389. doi: 10.1177/1094670512442806

Meng, M. D., Stavros, C., \& Westberg, K. (2015). Engaging fans through social media : Implications for team identification. Sport, Business and Management: An International Journal, 5(3), 199-217. doi: 10.1108/SBM-06-2013-0013

Meuser, M., \& Nagel, U. (1991). ExpertInneninterviews - vielfach erprobt, wenig bedacht: ein Beitrag zur qualitativen Methodendiskussion. In D. Garz \& K. Kraimer (Eds.), Qualitativ-empirische Sozialforschung: Konzepte, Methoden, Analysen (pp. 441-471). Opladen:Westdt. Verl.

Miloch, K.S. \& Lambrecht, K.W. (2006). Consumer awareness of sponsorship at grassroots sport events. Sport Marketing Quarterly, 15, 147-154.

Naraine, M. L., \& Parent, M. M. (2016). "Birds of a Feather": an institutional approach to Canadian national sport organizations' social-media use. International Journal of Sport Communication, 9(2), 140-162. doi: 10.1123/ijsc.2016-0010

O'Shea, M., \& Alonso, A. D. (2011). Opportunity or obstacle? A preliminary study of professional sport organisations in the age of social media. International Journal of Sport Management and Marketing, 10(3/4), 196-212. doi: 10.1504/ IJSMM.2011.044790

Pedersen, P. M. (2013). Reflections on communication and sport: On strategic communication and management. Communication \& Sport, 1(1/2), 55-67. doi: 10.1177/2167479 512466655

Pedersen, P. M. (2014). A commentary on social media research from the perspective of a sport communication journal editor. Communication \& Sport, 2(2), 138-142. doi: $10.1177 / 2167479514527428$

Pegoraro, A. (2010). Look who's talking-athletes on twitter: a case study. International Journal of Sport Communication, 3(4), 501-514. doi: 10.1123/ijsc.3.4.501

Pegoraro, A. (2013). Sport fandom in the digital world. In P. M. Pedersen (Ed.), The Routledge Handbook of Sport Communication (pp. 248-258). London: Routledge.

Peppers, D., \& Rogers, M. (2011). Managing customer relationships: A strategic framework. Hoboken, NJ: Wiley.

Pound, M. (2017). Skype interview on January $5^{\text {th }} 2017$.

Pronschinske, M., Groza, M. D., \& Walker, M. (2012). Attracting Facebook 'fans': The importance of authenticity and 
engagement as a social networking strategy for professional sport teams. Sport Marketing Quarterly, 21(4), 221-231

Raban, D. R., \& Rafaeli, S. (2007). Investigating ownership and the willingness to share information online. Computers in Human Behavior, 23(5), 2367-2382. doi: 10.1016/j. chb.2006.03.013

Rost, K., Stahel, L., \& Frey, B. S. (2016). Digital social norm enforcement: online firestorms in social media. PLOS ONE, 11(6). doi: 10.1371/journal.pone.0155923

Snyder, C. R. (2000). The past and possible futures of hope. Journal of Social and Clinical Psychology, 19(1), 11-28. doi: 10.1521/jscp.2000.19.1.11

Statista. (2016a). Internet usage worldwide 2016. Retrieved from https://www.statista.com/topics/1145/internet-usage-worldwide/

Statista. (2016b). Facebook users worldwide 2016. Retrieved from https://www.statista.com/statistics/264810/numberof-monthly-active-facebook-users-worldwide/

Stavros, C., Pope, N. \& Winzar, H. (2008). Relationship marketing in australian professional sport: an extension of the Shani Model. Sport Marketing Quarterly, 17(3), 135-145.

Stavros, C., Meng, M. D., Westberg, K., \& Farrelly, F. (2014). Understanding fan motivation for interacting on social media. Sport Management Review, 17(4), 455-469. doi: 10.1016/j. smr.2013.11.004

Tang, T., \& Cooper, R. (2011). The first online Olympics: The interactions between internet use and sports viewing. Journal of Sports Media, 6(1), 1-22. doi: 10.1353/jsm.2011.0002

Thompson, A.-J., Martin, A. J., Gee, S., \& Eagleman, A. N. (2014). Examining the development of a social media strategy for a national sport organisation: a case study of Tennis New Zealand. Journal of Applied Sport Management, 6(2), 42-64.

Van Noort, G., Voorveld, H. A. M., \& van Reijmersdal, E. A. (2012). Interactivity in brand web sites: cognitive, affective, and behavioral responses explained by consumers' online flow experience. Journal of Interactive Marketing, 26(4), 223-234. doi: 10.1016/j.intmar.2011.11.002

Vries, L. De, Gensler, S., \& Leeflang, P. S. H. (2012). Popularity of brand posts on brand fan pages: an investigation of the effects of social media marketing. Journal of Interactive Marketing, 26(2), 83-91. doi: 10.1016/j.intmar.2012.01.003

Wallace, L., Wilson, J., \& Miloch, K. (2011). Sporting Facebook: a content analysis of ncaa organizational sport pages and big 12 conference athletic department pages. International Journal of Sport Communication, 4(4), 422-444. doi: 10.1123/ijsc.4.4.422

Wang, P., Li, H., \& Suomi, R. (2016). Value co-creation in business via social media: a technology affordance approach. PACIS 2016 Proceedings. Retrieved from http://www.pacis2016. org/Abstract/AL/261.pdf

Wann, D. L., Friedman, K., McHale, M., \& Jaffe, A. (2003). The Norelco sport fanatics survey: Examining behaviors of sports fans. Psychological Reports, 92(3), 930-936. doi: 10.2466/PR0.92.3.930-936
Wann, D. L., Grieve, F. G., Zapalac, R. K., \& Pease, D. G. (2008). Motivational profiles of sport fans. Sport Marketing Quarterly, 17(1), 6-19.

Wann, D. L., Grieve, F. G., Zapalac, R. K., Visek, A. J., Partridge, J. A., Lanter, J. R. (2011). The importance of team identification in perceptions of trust of fellow and rival sport fans. In A. C. Earnheardt, P. M. Haridakis, \& B.S. Hugenberg (Eds.), Sports Fans, Identity, and Socialization: Exploring the Fandemonium (pp. 79-90). Lanham: Lexington Books.

Waters, R. D., Burke, K. A., Jackson, Z. H., \& Buning, J. D. (2011). Using Stewardship to Cultivate Fandom Online: Comparing How National Football League Teams Use Their Web Sites and Facebook to Engage Their Fans. International Journal of Sport Communication, 4(2), 163-177. http://doi. org/10.1123/ijsc.4.2.163

Watkins, E. (2004). Adaptive and maladaptive ruminative selffocus during emotional processing. Behaviour Research and Therapy, 42(9), 1037-1052. doi: 10.1016/j.brat.2004.01.009

Weikert, T. (2017). Face-to-face interview on January $4^{\text {th }} 2017$.

Williams, J., \& Chinn, S. J. (2010). Meeting relationship-marketing goals through social media: a conceptual model for sport marketers. International Journal of Sport Communication, 3(4), 422-437. doi: 10.1123/ijsc.3.4.422

Woratschek, H., Horbel, C., \& Popp, B. (2014). The sport value framework - a new fundamental logic for analyses in sport management. European Sport Management Quarterly, 14(1), 6-24. doi: $10.1080 / 16184742.2013 .865776$ 